\title{
Overcoming teacher burnout at special needs educational institutions: resources for reflection and on the meaning of life
}

\author{
Lyudmila Molchanova ${ }^{1, *}$, Alesya Kuznetsova ${ }^{1}$, and Elena Nikitina ${ }^{2}$ \\ ${ }^{1}$ Federal State Budgetary Educational Institution of Higher Education Kursk State Medical University \\ of the Ministry of Health of the Russian Federation, K. Marksa St., 3, Kursk, 305041, Russia \\ ${ }^{2}$ Federal State Budgetary Educational Institution of Higher Education "South-West State University", \\ Kursk, 50 years of October st. , 94, Kursk, 305040, Russia
}

\begin{abstract}
Background. Psychological practice has specified the need to search for resources for overcoming burnout that are reflective and meaningful - that help teachers explore the meaning of their lives defining corrective and preventive measures for reflective and meaningful regulation. Objective. To study the reflective and meaningful regulation of teacher burnout at special needs educational institution and to evaluate its effectiveness. Design. Twenty teachers from a special needs educational institution in Kursk, Russian Federation, participated in an experimental study. The researchers took measurements at two time points, baseline and follow-up. At baseline, we made a diagnostic assessment of the teachers' burnout, life principles, and reflectivity and searched for correlations among these indicators. At follow-up, we evaluated the teachers' burnout after a program of reflective and meaningful training for prophylaxis and overcoming of burnout. Results. We demonstrated empirically that Communicative Reflection, Process of Life, and Locus of Control-Life were personal resources for overcoming teacher burnout at the special needs educational institutions. Conclusion. eflective and meaningful training program for prophylaxis and overcoming of teacher burnout at a special needs educational institution was developed, tested, and found to be effective.
\end{abstract}

\section{Introduction}

Teachers at special needs educational institutions work under special conditions characterized by intensity and the particular tasks associated with correction of and compensation for children's physical and mental disabilities, conditions which can contribute to burnout [1-8].

There have been only a small number of studies of teacher burnout at special needs educational institutions; hence the relevance of this study, the results of which are a scientific novelty. This was shown by bibliometric analysis of publications in Russian retrieved from the electronic library elibrary.ru in response to the search request "Teacher

\footnotetext{
${ }^{*}$ Corresponding author: molchanowa.liuda@yandex.ru
} 
burnout at special needs educational institutions". The bibliometric analysis went back 10 years (from 2008 to 2018), and the number of publications retrieved was eight. This corresponded to $2.27 \mathrm{E}-5 \%$ of the total number of publications (for comparison, the same request found 37 scientific publications in the international citation database Scopus).

Foreign studies $[1 ; 2 ; 3 ; 12-14]$ on the issue of teacher burnout at special needs educational institutions, as well as Russian studies by Lobanova, Kondrakova, and Bursovoy (2014) [7], and Kupriyanchuk (2016) [5], were focused on phenomenology and genesis, determination, measurement, prevention, and correction. Yet no scientific publications dedicated to resources for overcoming teacher burnout at special needs educational institutions, resources that are reflective and meaningful - that help the teachers explore the meaning of their lives - were found in Scopus for the last 10 years. The search request ("Resources for overcoming burnout") found only one article for the entire period. "Regulation of teacher burnout" resulted in two articles, which corresponded to $6.485 \mathrm{E}-6 \%$.

The modern understanding of burnout in psychology refers to physical, emotional, and mental exhaustion (Orel, 2005), which can be mostly seen in human service professions [9; $10 ; 13]$. It includes the following elements: emotional burnout, depersonalization, and strong drive for professional success.

Burnout can be considered as a systemic quality of the subject of professional activity, represented by negative emotional States and attitudes towards themselves and their colleagues, their own success, as well as limited resource availability at different levels of psychological regulation.

Studies of the relationship between burnout and personal characteristics confirm its determinants, such as reflectivity, and value-oriented and conceptual features. It has been shown that the degree of burnout largely depends on the structural organization of its personal determinants $[7 ; 10]$.

Despite ongoing research interest in burnout, the identification of personal resources to overcome it has not been sufficiently studied.

Among Russian approaches to overcoming burnout are the system approach, the system-genetic approach [11], and the resource approach [6]. Particular attention is being paid to the metasystem approach [4], subject-activity approach [8].

Some Russian studies show that personal resources to overcome burnout should include the ability to change the impact of its external and internal manifestations from negative to positive, to block the impact of negative attitudes, and to preserve psychological stability.

Other authors believed that personal resources to overcome burnout included an understanding of the meaningfulness of one's life, self-actualization, and internality. She considers the ability to adapt and accumulate existing resources and to increase their number to be important. A sense of the meaningfulness of life, the availability of highly meaningful resources during professional activities, and the relevant meaningful conditions (related to synchronization of meanings in temporary loci of life) ensure the teacher's resistance to burnout.

According to Karpov's metasystem approach, the subject's metaregulative activities could be the integrating quality for its professional activities, presented at the professional, personal, and socio-psychological levels of the system. Karpov specified reflection and self-regulation as among the metacognitive abilities of personal resources for overcoming burnout [4].

From the standpoint of Mitina's (2011) subject-activity approach to overcoming burnout, the goal of psychological assistance should be the development of "subjectness" and the overcoming of professional and personal crises, because burnout is caused by a lack of subjectness, such as an inability to form relevant strategies, to set and adjust goals, to perform and evaluate activities [8].

Based on the subject-resource approach, it is possible to form individual potencies into 
subject-oriented and individual qualities, psychological resources related to different levels and systems of regulation: resources for professional and personal development, resources for protection from (resistance to) professional difficulties, resources for overcoming professional difficulties.

Foreign psychologists have considered the issue of overcoming burnout through various "resource" models. Recently, the resource approach to overcoming burnout is viewed increasingly as a promising area of research.

Psychological practice has specified the need to search for resources for overcoming burnout that are reflective and meaningful - that help teachers explore the meaning of their lives - defining corrective and preventive measures for reflective and meaningful regulation.

The reflective and meaningful regulation of burnout was described through significant mutual determination of reflectivity and meaningfulness, on the one hand, and burnout on the other.

The general hypothesis of the study affirmed that reflective and meaningful regulation of burnout among teachers at special educational institutions is a significant mutual determinant of reflectivity, meaningfulness, and burnout. Evaluation of its effectiveness by means of reflective and meaningful training for prophylaxis and for overcoming burnout yielded positive results.

Specific hypotheses of the study: There are statistically significant negative correlations between burnout and reflectivity and meaningful attitudes toward life; there is a statistically significant decline in burnout as a result of reflective and meaningful training for prophylaxis and overcoming of the problem.

\section{Methods Participants}

Twenty teachers from Kursk Boarding School, Russian Federation, a special needs educational institution, participated in the experimental study. Their ages were between 22 and 62 years; they had higher education, and professional experience ranging from 0.5 to 40 years; there were 18 female and 2 male teachers. The group of women was aged Xav. \pm $\sigma=38.56 \pm 13.21$, and their professional experience was Xav. $\pm \sigma=15.05 \pm 12.79$ years. The group of men was aged Xav. $\pm \sigma=28.00 \pm 7.07$, and their professional experience was Xav. $\pm \sigma=5.00 \pm 2.83$ years.

\section{Instruments and Measurements}

The experimental study involved two stages: the ascertaining (konstatiruiushchii) stage (with a measurement at baseline), and the control (kontrol'nyi) stage (with a measurement at follow-up). The ascertaining stage assessed the reflective and meaningful regulation of burnout, while the control stage evaluated the results of the reflective and meaningful training for prophylaxis and overcoming of burnout.

Both stages used the Professional (Emotional) Burnout questionnaire for teachers, methods for determining the Level of Reflectivity and the Meaning of Life Orientations Test.

Statistical processing of the results was performed with Statistica 11.0. Descriptive and comparative statistics and correlation analysis were used for quantitative and qualitative evaluation of the data (the statistical criterion for the significance of the differences was the Mann-Whitney U-Test).

\section{Procedure}


The study was performed in several stages.

The first stage included motivating the teachers and giving them information about the tasks, objectives, expected results, and practical importance of the study. They signed a statement of informed consent. Instructions based on the psychological and diagnostic materials were given to all participating teachers.

The second stage was the experimental study.

Only teachers at Kursk Boarding School who displayed a high level of burnout in the test performed at baseline, at the ascertaining stage of the experimental study, were chosen for evaluation of the effectiveness of the reflective and meaningful training for prophylaxis and overcoming of burnout. The experimental (EG) and control (CG) groups together comprised 20 teachers (10 per group). Equivalence of the experimental and control groups was achieved by randomization in accordance with professional criteria, considering the results of psychodiagnostics, as well as the personal desire of teachers to participate in the experiment.

Several working hypotheses were formulated for evaluating the effectiveness of the reflective and meaningful training for prophylaxis and overcoming of burnout, while their verification or refutation allowed us to draw solid conclusions:

Hypothesis H0 - At the ascertaining stage, groups CG (1) and EG (3) should be identical in their representation of burnout.

Hypothesis H1 - At the control stage, groups CG (2) and EG (4) should be significantly different in their representation of burnout, which may indicate the effectiveness of the reflective and meaningful training.

The nonparametric Mann-Whitney U-Test was used to evaluate the severity of burnout.

The third stage involved the statistical processing of the primary results.

The fourth and final stage included secondary diagnostics, whose results evaluated the effectiveness of the reflective and meaningful training for prophylaxis and overcoming of burnout, from the point of view of achieving all planned goals and objectives, as well as formulating the study's conclusions.

\section{Results}

Diagnostics of burnout using the Professional (Emotional) Burnout questionnaire for teachers confirmed an average level of severity, according to the following scales: Mental Burnout Index - Xav. $=64.55 \pm 8.23$, Emotional Exhaustion - Xav. $=21.60 \pm 5.68$, Depersonalization - Xav. $=9.50 \pm 5.74$, and Professional Success - Xav. $=33.45 \pm 5.98$. The evaluation of reflectivity and its structural components helped to specify the average severity, using techniques for determining the level of reflectivity: Reflectivity Level Xav. $=128.80 \pm 18.67$, Retrospective Reflection - Xav. $=34.85 \pm 5.25$, Real Reflection Xav. $=37.30 \pm 5.69$; Perspective Reflection - Xav. $=39.55 \pm 6.69$, as well as Communicative Reflection - Xav. $=36.25 \pm 5.17$. The indicators of life principles, which were obtained by using the Meaning of Life Orientations Test, also resulted in average values, in accordance with the following scales: Goals in Life - Xav. $=35.00 \pm 7.81$, Process of Life Xav. $=33.85 \pm 4.46$, Result of Life - Xav. $=27.75 \pm 3.26$, Locus of Control-I Xav. $=23.45 \pm 2.54$, Locus of Control-Life - Xav. $=33.30 \pm 4.71$, and Meaningfulness of Life - Xav. $=111.80 \pm 10.41$.

There were no statistically significant differences in reflectivity and life principles among the teachers at the special needs educational institution with different degrees of burnout.

The correlations between indicators of burnout and reflectivity, and also life principles, revealed the following results. Statistically significant correlations were found for negativity and moderate Emotional Exhaustion with the scales of life principles, such as 
Process of Life $\left(r=-0.46^{*}\right.$ with $\left.\mathrm{p}<0.05\right)$ and Locus of Control-Life $\left(r=-0.51^{*}\right.$ with $\mathrm{p}<0.05)$, as well as correlations of Depersonalization with Communicative Reflection $(\mathrm{r}=-0.51 *$ with $\mathrm{p}<0.05)$. It can be assumed that the teachers' perception of their lives as emotionally rich, interesting, and meaningful, their belief in their own abilities to autonomously make decisions and control the events of their lives, could reduce the feeling of emotional emptiness and fatigue, while analysis of the communicative process might reduce cynicism in their relationships with students and colleagues.

Thus, the general hypothesis of the study, affirming significant mutual determination of reflectivity, meaningfulness, and burnout among the teachers, was empirically confirmed.

Communicative Reflection, Process of Life, and Locus of Control-Life were concluded to be likely targets for correctional and preventive effects, in accordance with the results of study. This was consistent with the theoretical foundations of professional development of the personality: "Reflective processes of self-consciousness can have the character of both regulative (integrative) and meaning-generating mechanism, thereby determining the psychological content (methods and forms of activities) of the reflective resource of the personality and the individual trajectory for resolving intrapersonal contradictions" $[8, \mathrm{p}$. 204).

Reflective and meaningful training as an educational technology was performed due to its ability to maximally develop the subjectness of the teachers, which was expressed in self-realization, self-organization, and self-correction, and was represented in their professional development as health-preservation, aimed at prophylaxis and overcoming of burnout through optimization of reflective and meaningful resources.

The reflective and meaningful training for prophylaxis and overcoming of burnout included lectures and scientific/practical seminars on the issue of burnout. The training focused on the following tasks: cultivation of the desire for personal growth and professional self-realization through activation of professional interest; development of reflection through the training of reflective skills; formation of an appropriate emotion- and value-oriented attitude, and reorganization of the value system through training in the skills of an emotion- and value-oriented attitude towards oneself and others.

The complex of methods used in the reflective and meaningful training for prophylaxis and overcoming of burnout, including body-oriented, playful, and cognitive-behavioral approaches, positive therapy, as well as art therapy, being complementary to each other, made it possible to obtain a response at all levels: motivational, affective, intellectual, and behavioral.

The duration of the training was 120 hours: 48 sessions of 2.5 hours each for 6 months. The sessions were held twice a week, including lectures and scientific/practical seminars on the issue of burnout.

The scores at baseline confirmed an average severity of burnout among teachers from CG (1) and EG (3), with no significant differences between them, which proved the equivalence of the samples. The CG (1): Emotional Exhaustion - Xav. $=22.90 \pm 4.36$, Depersonalization - Xav. $=10.20 \pm 3.74$, Professional Success - Xav. $=31.60 \pm 5.50$, Mental Burnout Index - Xav. $=65.70 \pm 7.86$. The EG (3): Emotional Exhaustion Xav. $=20.30 \pm 6.73$, Depersonalization - Xav. $=7.80 \pm 7.00$, Professional Success Xav. $=35.30 \pm 6.13$, Mental Burnout Index - Xav. $=63.40 \pm 8.85$.

The results of the control stage allowed us to reach a conclusion about prophylaxis and overcoming of burnout. Burnout was considered the dependent variable in EG (3) and EG (4), while reflective and meaningful resources among teachers at the special needs educational institution were considered the independent variable. No significant differences were identified by the comparative analysis of burnout among teachers from CG (1) and CG (2). All the structural elements among the teachers from EG (3) and EG (4) turned out to be quite varied. Their average values decreased significantly (see Table 1). 
Table 1. Differences at Follow-up of Teacher Burnout at the Special Needs Educational Institution, Experimental Group (Mann-Whitney U-Test, $\mathrm{p} \leq 0.05$, U*emp. $\leq$ Ucr.)

\begin{tabular}{|c|c|c|c|c|c|c|c|}
\hline \multirow[t]{2}{*}{ No. } & \multirow[t]{2}{*}{ Indicator } & \multicolumn{2}{|c|}{ EG (3) } & \multicolumn{2}{|c|}{ EG (4) } & \multicolumn{2}{|c|}{ EG (3)-EG(4) } \\
\hline & & Xav. $\pm \sigma x$ & Qualitative & Xav. $\pm \sigma x$ & Qualitative & Uemp. & p \\
\hline 1 & $\begin{array}{l}\text { Emotional } \\
\text { Exhaustion }\end{array}$ & $\begin{array}{c}20.30 \pm \\
6.73\end{array}$ & Average & $\begin{array}{c}17.80 \pm \\
4.16\end{array}$ & Average & $11.00^{*}$ & 0.003 \\
\hline 2 & $\begin{array}{c}\text { Depersonalizatio } \\
n\end{array}$ & $\begin{array}{c}7.80 \pm \\
7.00\end{array}$ & Average & $\begin{array}{c}5.30 \pm \\
4.57\end{array}$ & Average & $14.50 *$ & 0.007 \\
\hline 3 & $\begin{array}{c}\text { Professional } \\
\text { Success }\end{array}$ & $\begin{array}{c}35.30 \pm \\
6.13\end{array}$ & Average & $\begin{array}{c}33.50 \pm \\
5.87\end{array}$ & Average & $15.50 *$ & 0.009 \\
\hline
\end{tabular}

Note. ${ }^{*}$ Significance of differences

Study of teacher burnout at the control stage in CG (2) and EG (4) allowed us to establish the significance of differences in indicators of all structural elements (see Table 2).

Table 2. Differences at Follow-up in Indicators of Teacher Burnout at the Special Needs Educational Institution, Control and Experimental Groups (Mann-Whitney U-Test, $\mathrm{p} \leq 0.05, \mathrm{U}^{*} \mathrm{emp} . \leq \mathrm{Ucr}$.)

\begin{tabular}{|c|c|c|c|c|c|c|c|}
\hline No. & \multirow{2}{*}{ Indicator } & \multicolumn{2}{|c|}{ CG (2) } & \multicolumn{2}{c|}{ EG (4) } & \multicolumn{2}{c|}{ CG (2)-EG (4) } \\
\cline { 3 - 8 } & & Xav. $\pm \boldsymbol{\sigma x}$ & Qualitative & $\begin{array}{c}\text { Xav. } \pm \\
\boldsymbol{\sigma x}\end{array}$ & $\begin{array}{c}\text { Qualita } \\
\text { tive }\end{array}$ & Uemp. & $\mathbf{p}$ \\
\hline 1 & $\begin{array}{c}\text { Emotional } \\
\text { Exhaustion }\end{array}$ & $\begin{array}{c}22.90 \pm \\
4.36\end{array}$ & Average & $\begin{array}{c}17.80 \pm \\
4.16\end{array}$ & $\begin{array}{c}\text { Averag } \\
\mathrm{e}\end{array}$ & $18.50^{*}$ & 0.017 \\
\hline 2 & $\begin{array}{c}\text { Depersonalizatio } \\
\mathrm{n}\end{array}$ & $\begin{array}{c}10.20 \pm \\
3.74\end{array}$ & Average & $\begin{array}{c}5.30 \pm \\
4.57\end{array}$ & $\begin{array}{c}\text { Averag } \\
\mathrm{e}\end{array}$ & $20.50^{*}$ & 0.026 \\
\hline 3 & $\begin{array}{c}\text { Professional } \\
\text { Success }\end{array}$ & $\begin{array}{c}31.60 \pm \\
5.50\end{array}$ & Average & $\begin{array}{c}33.50 \pm \\
5.87\end{array}$ & $\begin{array}{c}\text { Averag } \\
\mathrm{e}\end{array}$ & $20.50^{*}$ & 0.025 \\
\hline
\end{tabular}

Note. ${ }^{*}$ Significance of differences

Thus, hypotheses H0 and H1 were confirmed. The groups CG (1) and EG (3) were identical, while the groups CG (2) and EG (4) significantly differed in their severity of burnout.

\section{Discussion}

Theoretical and methodological analysis of the scientific literature testified to the fact that the psychological regulation of mental states is determined by different types of mechanisms: volitional mechanisms, value mechanisms, reflective mechanisms, semantic mechanisms, and self-regulatory mechanisms.

In our study, the reflective and meaningful regulation of teacher burnout included a reflective mechanism represented by the level of reflectivity and its structural elements, and a meaningfulness mechanism, represented by life principles.

Conclusions

The study of reflective and meaningful regulation of teacher burnout at the special needs educational institution and the evaluation of its effectiveness made it possible to draw the following conclusions.

First, burnout was significantly and negatively interrelated with reflectivity (Depersonalization - Communicative Reflection) and life principles (Emotional Exhaustion - Process of Life, Locus of Control-Life), and showed that teachers' perception of life as meaningful and interesting, their confidence in their own ability to control and manage it, might impede emotional exhaustion, while analysis of the communicative process could prevent negative attitudes towards students and colleagues.

Second, Communicative Reflection, Process of Life, and Locus of Control-Life were 
considered as personal resources for overcoming burnout.

Third, the reflective and meaningful training for prophylaxis and overcoming of burnout was effective, since the control stage (follow-up measurements) identified a statistically significant decrease in burnout.

Limitations

The main limitation of the study was the involvement of teachers from only one Russian city and one special (correctional) educational institution, located in Kursk. Therefore, the results of the study should be generalized with care to teachers at other special needs educational institutions in the future. This limitation can be overcome by involving teachers at special education institutions from several cities in the study.

Another limitation was that the study did not consider the impact of the corporate culture of the special needs educational institution and the teachers' interpersonal relationships on the reflective and meaningful regulation of burnout.

\section{References}

1. E.A. Bettini, K. Cheyney, J. Wang, C. Leko, Job design: An administrator's guide to supporting and retaining special educators. Intervention in School and Clinic 50(4) 221-225 (2015) https://doi.org/10.1177/1053451214532346

2. N.C. Brunsting, M.A. Sreckovic, K.L. Lane, Special education teacher burnout: A synthesis of research from 1979 to 2013. Education and Treatment of Children 37(4) 681-711 (2014) https://doi: 10.1353/etc.2014.0032

3. S. Hakan, S. Halis, Burnout and teacher self-efficacy among teachers working in special education institutions in Turkey. Educational Studies 40(4) 423-437 (2014) https://doi.org/10.1080/03055698.2014.930340

4. A.V. Karpov, Metacognitive determinants of mental burnout in professional activity Perspektivy Nauki i Obrazovania 42(6) 322-337 (2019).

5. E.V. Kupriyanchuk, Characteristic features of professional emotional burnout among teachers at special educational institutions: Comparative context 10(66) 660-669 (2016)

6. I.A. Kurapova, I.E .Dremina, L.V. Lezhnina, S.V. Korableva, Active and interactive methods for teaching psychological counseling. Issues and Trends in Interdisciplinary Behavior and Social Science. Proceedings of the 6th International Congress on Interdisciplinary Behavior and Social Sciences 181-184 (2018)

7. A.V. Lobanova, E.V Kondrakova, A.P. Bursova, Emotional burnout among teachers at correctional educational institutions. Scientific and methodical electronic magazine Concept 20 481-485 (2014)

8. L.M. Mitina, Z.N. Galina, Psychological conditions and factors for the improvement of higher professional education. Pedagogical journal of Bashkortostan 5, 202-212 (2011)

9. L.N. Molchanova, A.A. Kuznetsova, Reflexive and semantic regulation of the mental burnout condition among teachers of a special correctional educational institution and evaluation of its effectiveness, Perspectives of Science and Education 38(2), 212-228 (2019) https://doi.org/10.32744/pse.2019.2.16

10. L.N. Molchanova, Burnout among high school teachers in the context of professional success 348, 128-132 (Tomsk State University Bulletin, 2011)

11. V.E. Orel, Mental burnout syndrome 330 (Moscow, Institute of Psychology, RAS, 2005) 
12. P. Plichta, Occupational burdens in special educators working with intellectually disabled students Medycyna Pracy 65(2), 239-250 (2014)

13. A.V. Sitnikova, L.N. Molchanova, Psychological mechanisms of regulating mental burnout among teachers at special (correctional) educational institutions. Integrative Trends in Medicine and Education 1(1), 110-113 (2017)

14. S. Yotanyamaneewong, S. Juhari, Preventing teacher burnout: Exploring the perceptions of teachers for children with social, emotional and behavioural difficulties (SEBD) in Thailand. International Perspectives on Inclusive Education 2, 139-160 (2012) https://doi.org/10.1108/S1479-3636(2012)0000002012 